\title{
Türk Toplumundaki Gestasyonel Diabetes Mellitus'lu Gebelerde Helicobacter pylori Seropozitivitesi İnsidansı
}

\author{
Yeşim AKDEMİR ๑®, İrem DARKA ๑, Ülkü ÖZMEN ๑, Müge HARMA ๑, Mehmet İbrahim HARMA ๑ \\ Zonguldak Bülent Ecevit Üniversitesi Tıp Fakültesi, Kadın Hastalıkları ve Doğum Anabilim Dalı, Zonguldak \\ Bu makaleye yapılacak atıf: Akdemir Y, Darka İ, Özmen Ü, Harma M, Harma Mİ. Türk Toplumundaki Gestasyonel Diabetes Mellitus'lu Gebelerde Helicobacter pylori \\ Seropozitivitesi İnsidansı. Türk Diyab Obez 2019;3: 149-153.
}

\begin{abstract}
ÖZET
Amaç: $\mathrm{Bu}$ çalışmanın amacı Türk toplumundaki gebe kadınlarında Helicobacter pylori (HP) seropozitivitesinin GDM ile ilişkisini araştırmaktır.

Gereç ve Yöntemler: Eylül 2019- Kasım 2019 tarihleri arasında, Zonguldak Bülent Ecevit Üniversitesi Tip Fakültesi Kadın Hastalıkları ve Doğum AD’na başvuran 18-40 yaş arası, 26-37 haftalar arasında tekil gebeliği bulunan gebeler çalışmaya dahil edildi. Çoğul gebelikler, gebelik öncesi diyabet, hipertansiyon, hiperlipidemi, anemi ve ek sistemik hastalığı bulunan gebeler dışlandı. GDM tanısı almış 46 gebe GDM Grubu, diğer 28 gebe kontrol grubu olarak ayrıldı. Gebelerde HP IgA ve IgG antikorları ELISA yöntemi ile çalışıldı. IgA ve IgG antikorlarından herhangi biri pozitif olan hastalar $\mathrm{HP}(+)$, IgA ve IgG antikorlarından her ikisi de negatif olan hastalar HP(-) kabul edildi.

Bulgular: Yaş, gravida, parite, abortus, gestasyonel yaş, ultrasonografik yaş, ve tahmini fetal ağırlık her iki grupta da benzerdi. VKİ, AKŞ, açılı insülin ve HOMA-IR değerleri GDM grubunda kontrol grubuna göre anlamlı olarak yüksekti (sırasıyla $\mathrm{p}=0,018 ; \mathrm{p}=<0,001 ; \mathrm{p}=0,004$; $\mathrm{p}=0,001)$. GDM grubunda gebelerin \%77,3’ü, kontrol grubundaki gebelerin ise \%66,7’si HP (+) olarak saptandı fakat istatistiksel olarak fark bulunamadı. GDM grubunda HP IgG \%65,9 oranında pozitif iken, kontrol grubunda ise $\% 31,8$ olarak saptandı ( $\mathrm{p}=0,010)$. Diğer taraftan HP IgA insidansı açısından iki grup arasında fark gözlenmedi ( $\mathrm{p}=0,563)$. Her iki HP antikorunun da pozitif saptandığı gebelerin oranın ise GDM grubunda kontrol grubuna göre daha yüksek olduğu görüldü (\%28,2 vs \%10,71, p=0,008).

Sonuç: Türk toplumundaki GDM'li gebelerde HP seropozitivitesi insidansı GDM bulunmayan gebelerden yüksek olsa da istatistiksel olarak benzerdir. HP IgG seropozitivitesi ise GDM grubunda daha yüksek bulunmuştur. Bu bulgular Türk toplumundaki gebe kadınlarda HP enfeksiyonu ve gebelik komplikasyonlarının araştırılması açısından da faydalı olacaktır.
\end{abstract}

Anahtar Sözcükler: Gestasyonel diabetes mellitus, Helicobacter pylori, Gebelik

\section{Incidence of Helicobacter pylori Seropositivity in Turkish Pregnant Women with Gestational Diabetus Mellitus}

\begin{abstract}
Aim: The aim of this study to determine the Helicobacter pylori (HP) seropositivity in pregnant Turkish women and investigate the relationship with Gestational Diabetus Mellitus (GDM) with HP.

Material and Methods: A prospective case control study was conducted between September and November 2019 at Zonguldak Bulent Ecevit University, School of Medicine, Obstetrics and Gynecology Department. Pregnant women who were 18-40 years old, at 26-37 weeks of gestational age and had singleton pregnancies included. Exclusion criteria were: Multiple pregnancy, pre-gestational diabetes mellitus, hypertension, hyperlipidemia, anemia and other systemic diseases. Study group was consisted of 46 women with diagnosed as GDM due to $75 \mathrm{gr}$ oral glucose test and control group was consisted of 28 women. HP IgA ve IgG antibodies were measured using ELISA. Women were considered as HP (+) when IgA and/or IgG antibodies were positive, and considered as HP (-) when both antibodies were negative.
\end{abstract}

ORCID: Yeşim Akdemir / 0000-0002-8574-5065, İrem Darka / 0000-0002-5061-8146, Ülkü Özmen / 0000-0001-7979-4015, Müge Harma / 0000-0002-4327-674X, Mehmet İbrahim Harma / 0000-0002-9734-5253 
Results: No difference were seen in maternal age, gravidity, parity, abortus, gestational age, ultrasonographic age, and estimated fetal weight between two groups. Body mass index, fasting blood glucose and fasting insulin levels, and HOMA-IR were significantly higher in GDM group than control group ( $\mathrm{p}=0.018 ; \mathrm{p}=<0.001 ; \mathrm{p}=0.004 ; \mathrm{p}=0.001$ respectively). HP seropositivity were $77.3 \%$ in GDM group and $66.7 \%$ in control group but this difference was not statistically significant. HP IgG seropositivity was significantly higher in GDM group than control group $(65.9 \%$ vs $31.8 \%, \mathrm{p}=0,010)$. On the other hand HP IgA incidence was not different between two groups. Presence of both HP IgG and IgA seropositivity was higher in GDM group (28.2\% vs 10.71\%, GDM and control groups respectively, p= $0.008)$.

Conclusion: Incidence of HP seropositivity and HP IgG seropositivity in Turkish pregnant women with GDM were higher than pregnant women without GDM, but statistical significance could not be established in aspect of HP seropositivity. This data will be helpful for future studies that will investigate relation between HP seropositivity and pregnancy complications.

Key Words: Gestational diabetes mellitus, Helicobacter pylori, Pregnancy

\section{Gíriş}

Helicobacter pylori (HP) gram negatif, katalaz, üreaz, ve oksidaz pozitif, insan midesinde yaşayabildiği gösterilmiş tek bakteridir. Dünya genelinde enfeksiyon \%44 oranında saptanmıştır (1). Gebe kadınlarda HP enfeksiyonun prevalansı ise farklı coğrafi bölgelerde ve farklı sosyoekonomik șartlara bağlı olarak farklılık göstermektedir. Avrupa, Japonya ve Avustralya'da gebe kadınlardaki HP prevalansı \%20-30, Türkiye'de \%50-70, Mısır'da \%80 olarak saptanmıştır (2-6).

HP’nin kronik gastrit, peptik ülser ve gastrik kanser ile ilişkisi net olarak saptanmışken, özellikle gebelik dönemindeki ekstragastrik patolojilerle korelasyonu hakkındaki literatür verisi nispeten azdır (7). Çoğunluğu kesitsel olan bu çalışmalarda, HP enfeksiyonu hiperemezis gravidarum, preeklampsi, fetal gelişme geriliği, gestasyonel diabetes mellitus (GDM), ve spontan abortusla ilişkilendirilmiştir (8-10).

Metabolik hastalıklar ve HP arasındaki ilişki de merak konusu olmuş, HP enfeksiyonunun insulin resistansına yol açtığı, metabolik sendrom için risk faktörü olduğu, HP eliminasyonunun glukoz metabolizmanın regülasyonuna yardımcı olduğu gösterilmiştir (11-13). Cardaropoli ve ark. GDM ve HP enfeksiyonu arasında güçlü bir ilişki olduğunu, Alshareef ve ark. HP enfeksiyonunun GDM için risk faktörü olduğunu saptamışlardır $(14,15)$. Türkiye'deki yüksek HP prevalansının ise gestasyonel komplikasyonlarla, özellikle GDM ile ilişkisi bilinmemektedir. Biz de bu çalışmamızda Türk toplumundaki gebelerde HP seropozitivitesinin GDM ile ilişkisini araştırmayı amaçladık.

\section{GERECุ ve YÖNTEMLER}

Zonguldak Bülent Ecevit Üniversitesi Tip Fakültesi Etik Kurulu'dan onay alındiktan sonra (2019-164-02/10 Protokol no) Eylül 2019- Kasım 2019 tarihleri arasında, Zonguldak Bülent Ecevit Üniversitesi Sağlık Uygulama ve Araştırma Merkezi Kadın Hastalıkları ve Doğum AD’ na başvuran gebeler değerlendirildi. 18-40 yaş arası, 26-37 haftalar arasında tekil gebeliği bulunan gebeler çalışmaya dahil edildi. Çoğul gebelikler, gebelik öncesi diyabet, hipertansiyon, hiperlipidemi, anemi ve ek sistemik hastalı̆̆ 1 bulunan gebeler dışlandı. Tüm katılımcılardan ayrıntılı bilgilendirilmiş onam alındı. Uluslararası Diyabet ve Gebelik Çalışma Grupları Birliği (IADPSG) önerisine göre 75 gr oral glukoz yükleme öncesi açlık glukoz $\geq 92$, yükleme sonrası 1 . saat kan glukoz $\geq 180$ ya da 2 . saat kan glukoz $\geq$ 153 değerlerinden birinin varlığı halinde GDM tanısı almış 46 gebe GDM Grubu, diğer 28 gebe kontrol grubu olarak ayrild.

Gebelerin demografik ve obstetrik özellikleri kaydedildi. Açlık glukoz ve açlık insülin değerleri ve insülin resistansı HOMA-IR [Açlık insülin (mIU / L)/ Açlık glukoz (mg / dL) / 405] formulasyonu ile hesapland. HP IgA ve IgG antikorları ise ELISA yöntemi ile çalışıldı. HP IgA ve IgG antikorları için $<9$ negatif, 9-11 ara değer, $>11$ pozitif kabul edildi. IgA ve IgG antikorlarından herhangi biri pozitif olan hastalar $\mathrm{HP}(+)$, IgA ve IgG antikorlarından her ikisi de negatif olan hastalar HP(-) kabul edildi.

Çalışmanın istatistikleri SPSS 19.0 paket programında yapıldı. Nitel değişkenlere ait tanımlayıcı istatistikler frekans ve yüzde ile nicel değişkenler aritmetik ortalama, medyan, minimum ve maksimum değerleriyle verilmiştir. Normal dağılım göstermeyen nicel değişkenlerin iki grup arası karşılaştırmalarında Mann Whitney U testi kullanılmıştır. Sürekli değişkenlerin normal dağılıma uygunluğu Shapiro Wilk testi ile değerlendirildi. Nitel değişkenlerin gruplar arası karşılaştırmalarında Yates ki-kare testi kullanıldı. Çalışmadaki tüm istatistiksel analizlerde $\mathrm{p}$ değeri 0,05in altındaki sonuçlar istatistiksel olarak anlamlı kabul edildi.

\section{BULGULAR}

Gruplar arası yapılan karşılaştırmada yaş, gravida, parite, abortus, ve önceki vajinal doğum sayıları, son adet tarihine göre gestasyonel yaş, ultrasonografik yaş, ve tahmini fetal 
ağırlık açısından farklılık gözlenmezken, önceki sezaryen doğum sayısı kontrol grubunda daha yüksek bulundu (0 [02] vs 1 [0-3] $\mathrm{p}=0,017$ ) (Tablo 1). Ayrica obezite ve GDM arasında direkt ilişki olduğu bilindiğinden, beklenildiği gibi VKİ GDM grubunda kontrol grubundan yüksek saptandı $(31,4[22,89-55,66]$ vs $29,7[21,48-49,13], \mathrm{p}=0,029)$.

Grupların metabolik ve HP enfeksiyonu parametreleri Tablo 2'de gösterilmiştir. AKŞ, açlık insülin ve HOMA-IR değerleri GDM grubunda kontrol grubuna kıyasla anlamlı olarak daha yüksek görüldü.

HP IgA veya HP IgG antikorlarından en az biri pozitif olan gebelerin HP seropozitif olduğu kabul edilip yapılan karşılaştırma sonucunda, GDM grubunda gebelerin $\% 77,3$ ' ü, kontrol grubundaki gebelerin ise \%66,7’si HP (+) olarak saptandi. Her iki grup arasında istatistiksel olarak fark gözlenmedi $(p=0,363)$. Bununla beraber HP IgG seropozitivitesi GDM grubunda kontrol grubundan daha yüksek bulundu. GDM grubunda HP IgG \%65,9 oranında pozitif iken, kontrol grubunda ise $\% 31,8$ olarak saptand 1 $(p=0,010)$. Diğer taraftan HP IgA insidansı açısından iki grup arasında fark gözlenmedi. Her iki HP antikorunun da pozitif saptandığ gebelerin oranın ise GDM grubunda kontrol grubuna göre daha yüksek olduğu görüldü (\%28,2 vs $\% 10,71$, sirasiyla GDM ve kontrol grubu, $\mathrm{p}=0,008$ ).

\section{TARTIȘMA}

Çalışmamızın sonucunda HP seropozitivitesi insidansının GDM'li gebelerde GDM bulunmayan gebelerden yüksek olsa da istatistiksel olarak benzer olduğu bulundu. HP seropozitivitesin GDM'li gebelerde $\% 77$ olduğu saptanarak, bu oranın Türkiye'de daha önce bildirilmiş prevalans değerlerden daha yüksek olduğu görüldü (4).

HP enfeksiyonunu geçirmiş hemen hemen tüm bireylerde spesifik IgG antikoru yüksek seviyede saptanırken, olguların sadece $2 / 3$ 'ünde spesifik IgA antikoru cut-off değerin üzerinde saptanır. HP IgA seviyelerinin persiste kronik enfeksiyonda yükseldiği, IgA antikoru üretiminin HP Cag A (+) enfeksiyon ile ilişkili olduğu ve peptik ülser, atrofik gastrit, intestinal metaplazi, ve gastrik kanser gibi ciddi komplikasyonlara eşlik ettiği saptanmıştır (16-19). Biz

Tablo 1: Grupların karakteristikleri.

\begin{tabular}{|c|c|c|c|}
\hline & GDM $n=46$ & Kontrol $n=28$ & $\mathbf{p}$ \\
\hline Yaş $^{*}$ & $30(18-42)$ & $29,5(18-42)$ & 0,506 \\
\hline $\mathbf{V K} \dot{I}^{a \star}$ & $31,4(22,89-55,66)$ & $29,7(21,48-49,13)$ & 0,029 \\
\hline Gravida $^{\star}$ & $2(1-7)$ & $2(1-4)$ & 0,180 \\
\hline Parite & $1(0-3)$ & $1(0-10)$ & 0,156 \\
\hline Vajinal doğum $(\mathbf{n})^{*}$ & $0(0-4)$ & $0(0-4)$ & 0,363 \\
\hline Sezaryen $(\mathbf{n})^{\star}$ & $0(0-2)$ & $1(0-3)$ & 0,017 \\
\hline $\operatorname{Abortus}(\mathbf{n})^{*}$ & $0(0-2)$ & $0(0-3)$ & 0,179 \\
\hline Gestasyonel yaş $\left(\mathrm{SAT}^{\mathrm{b}}\right)(\text { hafta })^{*}$ & $28,5(26-37)$ & $29(26-37)$ & 0,256 \\
\hline Ultrasonografik yaş ortalaması (hafta) ${ }^{\star}$ & $29(24-38)$ & $30(25-38)$ & 0,210 \\
\hline TFA $^{c}(g r)^{*}$ & $1972,5(620-3752)$ & $2124,50(782-3604)$ & 0,125 \\
\hline
\end{tabular}

$\mathrm{n}=$ hasta sayısı, ${ }^{*}$ medyan (min-max), ${ }^{\mathrm{a}}$ Vücut Kitle İndeksi, ${ }^{\mathrm{b}}$ Son adet tarihi, ${ }^{\mathrm{c}}$ Tahmini fetal ağırlık

Tablo 2: Grupların metabolik ve Helicobacter pylori enfeksiyonu parametreleri.

\begin{tabular}{lccc}
\hline & GDM $\mathbf{n = 4 6}$ & Kontrol $\mathbf{n = 2 8}$ & $\mathbf{p}$ \\
\hline AKŞS $^{\mathrm{a}}(\mathbf{m g} / \mathbf{d L})^{*}$ & $94,5(66-163)$ & $82(74-100)$ & $<\mathbf{0 , 0 0 1}$ \\
\hline Açlik insülin (mIU/L) $^{*}$ & $16,24(4,07-83,52)$ & $9,62(0,21-24,85)$ & $\mathbf{0 , 0 0 4}$ \\
\hline HOMA-IR $^{*}$ & $3,65(0,65-21,49)$ & $2,15(0,04-6,05)$ & $\mathbf{0 , 0 0 1}$ \\
\hline HP $^{\mathrm{b}}$ seropozitivitesi (n)\% & $(34) 77,3$ & $(14) 66,7$ & $\mathbf{0 , 3 6 3}$ \\
\hline HP $^{\mathrm{b}}$ IgG (+) (n) \% & $(29) 65,9$ & $(7) 31,8$ & $\mathbf{0 , 0 1}$ \\
\hline HP $^{\mathrm{b}}$ IgA (+) (n)\% & $(17) 41,5$ & $(10) 47,6$ & $\mathbf{0 , 5 6 3}$ \\
\hline HP $^{\mathrm{b}}$ IgG ve HP ${ }^{\mathrm{b}}$ IgA (+) (n)\% & $(13) 28,2$ & $(3) 10,71$ & $\mathbf{0 , 0 0 8}$ \\
\hline
\end{tabular}

$\mathrm{n}=$ hasta sayısı, ${ }^{*}$ medyan (min-max), ${ }^{\mathrm{a} A c ̧ l l k ~ k a n ~ s ̧ e k e r i, ~}{ }^{\mathrm{b}}$ Helicobacter pylori 
çalışmamızda, HP IgG seropozitivitesinin GDM grubunda kontrol grubundan daha yüksek olduğunu saptadık fakat HP IgA seropozitivitesi ise her iki grupta da benzer oranlardayd.

Helicobacter pylori enfeksiyonu ve diabetes mellitus (DM) ilişkisini inceleyen çalışmaların birçoğunda Tipl DM ve Tip2 DM hastalarındaki HP prevalansının daha yüksek olduğu saptanırken (20-22), bazı çalışmalarda bu ilişki saptanamamıştır $(23,24)$. Koh ve ark. DM hastalarında bozulmuş olan hücresel ve humoral immunitenin HP enfeksiyonu oluşumuna yatkınlık yarattığını bildirmiș (25), Perdichizzi ve ark. ise DM hastalarında regüle olmayan glukoz metabolizmasının gastrik mukozada kimyasal değişiklikler yaratarak HP kolonizasyonuna zemin hazırladığını söylemişlerdir (26). Öte yandan HP enfeksiyonunun proenflamatuar sitokinleri ve reaktif oksijen türlerim (ROT) oluşumunu artırıp, insülininsülin reseptör kompleksi fonksiyonunu bozarak, insülin aktivitesini azalttığını (27), ayrıca enerji homeastazı, insülin duyarlılığı ve glukoz homeostazının sağlanmasında önemli iki hormon olan leptin ve ghrelin regülasyonuna etkisi olduğu da gösterilmiştir (28).

Birçok çalışmada HP enfeksiyonu ile insülin rezistansı arasındaki ilişki araştırılmış ve HP ile insülin rezistansı arasında pozitif korelasyon saptanmıştır (27,29-32). Bununla beraber tersini söyleyen yayınlar da mevcuttur. Alshareef ve ark. Sudan'lı gebe kadınlarda HP IgG seropozitivitesi ve insülin resistansı arasında bir ilişki saptayamamış (15), Polyzos ve ark. ise 2120 olguyu dahil ettikleri meta analizlerinde aynı sonuca ulaşmışlardır (33).

Gen ve ark. HP eradikasyonunun insülin resistans1, lipid anormallikleri, ve düşük dereceli enflamasyonu düzeltici etkisi olduğunu söylerken (34), yakın zamanda yayınlanmış dispepsi şikayeti olup $\mathrm{HP}(+) 934$ olgunun dahil edildiği başka bir meta-analiz ise, HP enfeksiyonunun eradike edilmesi ile insülin resistansı, açlık kan glukozu, HDL, trigliserid, LDL, ve CRP değerleri açısından iyileşme gösterilememiştir (35).

Her ne kadar insülin resistansı ve metabolik parametreler ile HP enfeksiyonun direkt etkisi ya da HP eradikasyonunun bu parametreler üzerine düzeltici etkisi tartışmalı olsa da; Cardarapoli ve ark. yaptıkları prospektif kohort çalışmada HP seropozitif gebelerde, HP seronegatif gebelere oranla GDM gelişme oranını 1.93 olarak saptamış ve HP ile GDM ilişkisini ilk defa göstermişlerdir (14).

\section{SONUÇ}

Türk toplumundaki GDM'li gebelerde HP seropozitivitesini araştıran bir çalışmaya literatürde rastlanmamıştır. Çalışmamızın sonucunda HP seropozitivitesi insidansının
GDM'li gebelerde GDM bulunmayan gebelerden yüksek olsa da istatistiksel olarak benzer olduğu fakat HP IgG seropozitivitesinin ise GDM grubunda istatistiksel olarak daha yüksek olduğunu bulduk. Bu bulgular Türk kadın popülasyonundaki HP seropozitivitesi ve gebelik komplikasyonlarının araştırılması açısından da faydalı olacaktır. Bununla beraber örneklem grubumuzun rölatif olarak az sayıda olması, ve HP parametreleri ile insülin rezistansı gibi metabolik parametreler arasındaki ileri istatistiksel karşılaştırmaların yapılamamış olması çalışmamızın limitasyonları olarak değerlendirilebilir.

$\mathrm{Bu}$ bilgiler 1şığında, HP seropozitivitesi ve GDM, preeklampsi, fetal gelişme geriliği, erken doğum gibi gebelik komplikasyonları arasındaki ilişkiyi net bir şekilde ortaya koyabilmek için daha fazla sayıda prospektif çalışmaya ihtiyaç olduğunu düşünmekteyiz.

\section{KAYNAKLAR}

1. Zamani M, Ebrahimtabar F, Zamani V, Miller WH, AlizadehNavaei R, Shokri-Shirvani J, Derakhshan MH. Systematic review with meta-analysis: The worldwide prevalence of Helicobacter pylori infection. Aliment Pharmacol Ther. 2018;47(7):868-876.

2. Weyermann M, Rothenbacher D, Gayer L, Bode G, Adler G, Grab D, Flock F, Brenner H. Role of Helicobacter pylori infection in iron defciency during pregnancy. Am J Obstet Gynecol. 2005; 192: 548-553.

3. Kitagawa $M$, Natori $M$, Katoh $M$, Sugimoto $K$, Omi $H$, Akiyama Y, Sago H. Maternal transmission of helicobacter pylori in the perinatal period. J Obstet Gynaecol Res. 2001; 27: 225-230.

4. Karaer A, Ozkan O, Ozer S, Bayir B, Kilic S, Babur C, Danişman N. Gastrointestinal symptoms and Helicobacter pylori infection in early pregnancy. A seroepidemiologic study. Gynecol Obstet Invest. 2008; 66: 44-46.

5. Berker B, Soylemez F, Cengiz SD, Kose SK. Serologic assay of helicobacter pylori infection. Is it useful in hyperemesis gravidarum? J Reprod Med. 2003; 48: 809-812.

6. Bassily S, Frenck RW, Mohareb EW, Wierzba T, Savarino S, Hall E, Kotkat A, Nafcy A, Hyams KC, Clemens J. Seroprevalence of helicobacter pylori among Egyptian newborns and their mothers: A preliminary report. Am J Trop Med Hyg. 1999; 61: 37-40.

7. Sugano K, Tack J, Kuipers EJ, Graham DY, El-Omar EM, Miura S, Haruma K, Asaka M, Uemura N, Malfertheiner P; faculty members of Kyoto Global Consensus Conference. Kyoto global consensus report on helicobacter pylori gastritis. Gut. 2015;64(9):1353-1367.

8. Cardarapoli S, Rolfo A, Todros T. Helicobacter pylori and pregnancy related disorders. World J Gastroenterol. 2014; 20(3):654-664. 
9. Zhan Y, Si M, Li M, Jiang Y. The risk of helicobacter pylori infection for adverse pregnancy outcomes: A systemic review and meta-analysis. Helicobacter. 2019; 24:e12562.

10. Göymen A, Özdurak İ, Özkaplan ŞE, Şimsek Y, Avcı F, Akpak YK. The relationship between the helicobacter pylori seropositivity with systemic and local oxidative status and hyperemesis gravidarum: A pilot study. J Matern Fetal Neonatal Med. 2018;31(9):1204-1208.

11. Bonfigli AR, Boemi M, Festa R, Bonazzi P, Brandoni G, Spazzafumo L, Olivieri F, Ceriello A, Genovese S, Testa R. Randomized, double-blind, placebo-controlled trial to evaluate the effect of Helicobacter pylori eradication on glucose homeostasis in type 2 diabetic patients. Nutr Metab Cardiovasc Dis. 2016;26(10):893-898.

12. Georges JL, Rupprecht HJ, Blankenberg S, Poirier O, Bickel C, Hafner G, Nicaud V, Meyer J, Cambien F, Tiret L; AtheroGene Group. Impact of pathogen burden in patients with coronary artery disease in relation to systemic infammation and variation in genes encoding cytokines. Am J Cardiol. 2003;92(5):515521.

13. Manco M, Putignani L, Bottazzo GF. Gut microbiota, lipopolysaccharides, and innate immunity in the pathogenesis of obesity and cardiovascular risk. Endocr Rev. 2010;31:817844.

14. Cardaropoli S, Giuffrida D, Piazzese A, Todros T. Helicobacter pylori seropositivity and pregnancy-related diseases: A prospective cohort study. J Reprod Immunol. 2015;109:41-47.

15. Alshareef SA, Rayis DA, Adam I, Gasim GI. Helicobacter pylori infection, gestational diabetes mellitus and insulin resistance among pregnant Sudanese women. BMC Res Notes. 2018;11(1):517.

16. Salomaa-Räsänen A, Kosunen TU, Karjalainen J, Aromaa A, Knekt P, Sarna S, Rautelin H. IgA antibodies in persisting helicobacter pylori infection in Finnish adults. Clin Microbiol Infect. 2006;12(3):236-240.

17. Han JW, Kamber M. Data mining: Concepts and techniques. Morgan Kaufmann Publishers, USA 2001: 16.

18. Domellof L. Reversal of gastric atrophy after Helicobacter pylori eradication: Is it possible or not? Am J Gastroenterol. 1998;93:1407-1408.

19. Gao H, Wang JY, Shen XZ, Liu JJ. Effect of helicobacter pylori infection on gastric epithelial cell proliferation. World J Gastroenterol. 2000;6:442-444.

20. Bener A, Micallef R, Afifi M, Derbala M, Al-Mulla HM, Usmani MA. Association between type 2 diabetes mellitus and helicobacter pylori infection. Turk J Gastroenterol. 2007;18:225-229.

21. de Luis DA, de la Calle H, Roy G, de Argila CM, Valdezate S, Canton R, Boixeda D. Helicobacter pylori infection and insulin-dependent diabetes mellitus. Diabetes Res Clin Pract. 1998;39(2):143-146.

22. Devrajani BR, Shah SZ, Soomro AA, Devrajani T. Type 2 diabetes mellitus: A risk factor for Helicobacter pylori infection: A hospital based case-control study. Int J Diabetes Dev Ctries. 2010;30(1):22-26.
23. Anastasios R, Goritsas C, Papamihail C, Trigidou R, Garzonis P, Ferti A. Helicobacter pylori infection in diabetic patients: prevalence and endoscopic findings. Eur J Intern Med. 2002;13(6):376.

24. Demir M, Gokturk HS, Ozturk NA, Kulaksizoglu M, Serin E, Yilmaz U. Helicobacter pylori prevalence in diabetes mellitus patients with dyspeptic symptoms and its relationship to glycemic control and late complications. Dig Dis Sci. 2008;53(10):2646-2649.

25. Koh GC, Peacock SJ, van der Poll T, Wiersinga WJ. The impact of diabetes on the pathogenesis of sepsis. Eur J Clin Microbiol Infect Dis. 2012;31(4):379-388.

26. Perdichizzi G, Bottari M, Pallio S, Fera MT, Carbone M, Barresi G. Gastric infection by Helicobacter pylori and antral gastritis in hyperglycemic obese and in diabetic subjects. New Microbiol. 1996;19(2):149-154.

27. Aslan M, Horoz M, Nazligul Y, Bolukbas C, Bolukbas FF, Selek $\mathrm{S}$, Celik H, Erel O. Insulin resistance in $\mathrm{H}$. pylori infection and its association with oxidative stress. World J Gastroenterol. 2006;12(42):6865-6868.

28. Francois F, Roper J, Joseph N, Pei Z, Chhada A, Shak JR, de Perez AZ, Perez-Perez GI, Blaser MJ. The effect of $\mathrm{H}$. pylori eradication on meal-associated changes in plasma ghrelin and leptin. BMC Gastroenterol. 2011;11:37.

29. Aydemir S, Bayraktaroglu T, Sert M, Sokmen C, Atmaca H, Mungan G, Gun BD, Borazan A, Ustundag Y. The effect of Helicobacter pylori on insülin resistance. Dig Dis Sci. 2005;50(11):2090-2093.

30. Eshraghian A, Hashemi SA, Jahromi AH, Eshraghian $H$, Masoompour SM, Davarpanah MA, Eshraghian K, Taghavi SA. Helicobacter pylori infection as a risk factor for insulin resistance. Dig Dis Sci. 2009;54(9):1966-1970.

31. Vafaeimanesh J, Parham M, Seyyedmajidi M, Bagherzadeh M. Helicobacter pylori infection and insulin resistance in diabetic and nondiabetic population. Sci World J. 2014;2014:391250

32. Tamura T, Morita E, Kawai S, Sasakabe T, Sugimoto Y, Fukuda N, Suma S, Nakagawa H, Okada R, Hishida A, Naito M, Hamajima N, Wakai K. No association between Helicobacter pylori infection and diabetes mellitus among a general Japanese population: A cross-sectional study. Springerplus. 2015;4(1):602.

33. Polyzos SA, Kountouras J, Zavos C, Deretzi G. The association between Helicobacter pylori infection and insulin resistance: A systematic review. Helicobacter. 2011;16:79-88.

34. Gen R, Demir M, Ataseven H. Effect of Helicobacter pylori eradication on insulin resistance, serum lipids and low-grade inflammation. South Med J. 2010;103(3):190-196.

35. Upala S, Sanguankeo A, Saleem SA, Jaruvongvanich V. Effects of Helicobacter pylori eradication on insülin resistance and metabolic parameters: A systemic review and meta-analysis. Eur J Gastroenterol Hepatol. 2017;29(2):153-159. 
